\title{
Parent perceptions of literacy learning of their young children on the autism spectrum in their first year of schooling
}

A growing body of research suggests children on the autism spectrum demonstrate reading difficulties (Arciuli, Stevens, Trembath, \& Simpson, 2013; McIntyre et al., 2017; Nation, Clarke, Wright, \& Williams, 2006). This is of concern, given that an estimated $2.75 \%$ of Australian primary school students present with autism spectrum disorder (ASD, Australian Institute of Health and Welfare, 2017) which equates to one student with ASD in every second Australian classroom. Autism is a pervasive disorder characterised by core challenges in social communication skills as well as the presence of unusually strong interests and/or repetitive behaviors (American Psychiatric Association, 2013). Co-morbid diagnoses tend to be the rule, rather than the exception, with elevated rates of co-diagnosis of ADHD, intellectual disability (approximately 30\%, CDC, 2018), mental health conditions (e.g., anxiety, see Adams, Young, \& Keen, 2019), and medical conditions such as epilepsy (e.g., Kohane et al., 2012). Further, more than $90 \%$ of children often show elevated levels of challenging behaviours (e.g., Jang, Dixon, Tarbox, \& Granpeesheh, 2011; Matson, Wilkins, $\&$ Macken, 2008). It may be that both the core characteristics (i.e. social communication and repetitive behaviours/restricted interests) and common co-morbidities (e.g., intellectual impairment) associated with ASD result in reading vulnerabilities in this population.

There are a number of potential pathways through which core ASD characteristics and associated challenges may impact on reading. Co-morbid intellectual disability may be associated with slower learning and lower performance compared to those without an intellectual disability (e.g., see review by Keen, Webster, \& Ridley, 2015). Further, associated common delays in language acquisition may make children vulnerable to later challenges in reading, in line with the Simple View of Reading (Murphy, Justice, O'Connell, Pentimonti, \& Kaderavek, 2016; Nation, Cocksey, Taylor, \& Bishop, 2010). Socialcommunication differences may lead to reduced engagement in early literacy activities that may inhibit development of precursor literacy skills (e.g., Westerveld \& van Bysterveldt, 2017). Finally, cognitive styles described as underlying autism such as a detail-focused cognitive style (cf. central coherence theory; Happé \& Frith, 2006), difficulties with executive functioning (i.e., planning, shifting set, see Geurts et al., 2004), and challenges in taking others' perspectives (i.e., theory of mind, for a review see Baron-Cohen, 2000) may impact upon early learning processes including engagement, and acquisition of skills from predominantly social learning contexts. As such, understanding the perspectives of a key social support, in this case the parents, is vital to informing the literacy supports for this population.

\section{Literacy development in children on the autism spectrum}

One of the most important academic skills children learn during the early years of schooling is reading. It is concerning, therefore, that children on the autism spectrum often struggle in their reading development (Arciuli et al., 2013; Brown, Oram-Cardy, \& Johnson, 2013; Huemer \& Mann, 2010). In an effort to better understand why this group of children is at particular risk of reading difficulties, research has started to investigate the early reading skills of children on the autism spectrum (for a review see Westerveld, Trembath, Shellshear, and Paynter, 2016), both prior to school-entry (e.g., Westerveld et al., 2017) and during the first few years of schooling (e.g., Dynia et al., 2016; Westerveld, Paynter, O'Leary, \& 
Trembath, 2018). Taken together the results from these studies have illuminated early challenges in (pre-) reading skills in this population that cannot be explained by a diagnosis of autism, poor cognition, or language weaknesses alone. Considering the important role parents play in their children's literacy learning, the current study not only sought to obtain parents' perceptions about the importance of literacy learning for their young children on the autism spectrum, it also asked what strategies parents used to engage their children in literacy-related activities, and their opinions regarding the literacy learning supports their children received in the school environment.

\section{Parents' role in supporting early literacy learning}

Parents hold a wealth of information about their children and play a key role in supporting their early literacy development (Chandler-Olcott \& Kluth, 2009). From birth children begin to develop emergent literacy knowledge, skills and attitudes through interactions with literacy-related materials in the home, as well as through observations and interactions with family members and other carers (Fleury \& Schwartz, 2017; Pullen \& Justice, 2003). Parental activities such as reading aloud to their children and engaging in reading and writing tasks which children observe, assist children to learn about the forms and functions of print and the relationship between oral and written language (Puranik, Lonigan, \& Kim, 2011; Teale \& Sulzby, 1986). Such activities are known to have a discernible impact on children by the time they enter pre-school at age 3-4 (van Bergen, van Zuijen, Bishop, \& de Jong, 2017). However, parents' continued engagement in literacy activities with their children is considered an important factor in ongoing reading development once children start school (van Bergen, et al., 2017).

Chandler-Olcott and Kluth (2008) identified a range of ways that parents of children with disabilities generally support their children's literacy learning. These included embedding some form of literacy and language events within their daily routines; engaging in literacy practices specific to particular communities of practice such as church; volunteering in classrooms; and communicating with teachers. In addition, Zablotsky, Boswell, and Smith (2012) suggested that parents of children on the autism spectrum are more likely to attend parent-teacher conferences and assist with homework than parents of typically developing children. However, these authors acknowledged that little is known about the specific literacy support provided by parents to their children on the autism spectrum, or their literacy-related collaborations with their children's teachers.

\section{Family-school partnerships}

As children on the autism spectrum are increasingly enrolled in mainstream education settings with and without support, there is a need for strong parent and teacher collaboration to achieve a supportive academic environment beyond that required by their typically developing peers (Saggers et al., 2015; Schultz, Able, Sreckovic, \& White, 2016). Parents of children on the autism spectrum can provide insight on their child's strengths and vulnerabilities, which can be utilised by teachers to tailor learning experiences (Volkmar, 2014). Extensive evidence exists for the effectiveness of active parental involvement in improving academic and social outcomes for students with disabilities (Shepherd \& Kervick, 2016) and it is now commonly acknowledged that parental involvement is a crucial 'best practice' in the education of students with autism spectrum disorders. However processes are seldom operationalised and sustained (Azad \& Mandell, 2016). For example, Tucker and Schwartz (2013) found that although parents value regular and timely communication with 
teachers, schools struggle to sustain consistent, reliable, two-way communication. When positive partnerships are established between schools and families with children on the autism spectrum, they have been found to lead to more effective implementation of intervention (Blair, Lee, Cho, \& Dunlap, 2011), improved relationships and greater satisfaction with care (Renty \& Roeyers, 2006), improved outcomes for children (Azad, Marcus, Sheridan, \& Mandell, 2018), and enhanced family quality of life (Goldrich Eskow, Summers, Chasson, \& Mitchell, 2018).

How schools initially engage and position parents, along with the nature of the collaboration are pivotal to successful partnerships. The term parent partnership suggests an equitable relationship in which families, teachers and other professionals agree to share and build on each other's expertise and resources and engage in decision-making that will directly benefit children, and indirectly benefit other family members and professionals (Turnbull, Turnbull, Erwin, Soodak, \& Shogren, 2015). Eskow et al. (2018) argue that other terms used to describe how schools work with families, for example parent involvement, parent education, and parent training imply that schools are operating from a position of power with information flowing in one direction from the school to families. Further, it suggests a deficit view of parents' expertise, and ignores the specific knowledge that parents have about their children with autism, devaluing the ways that parents have devised to engage successfully with their children - ways that could assist schools in tailoring literacy learning experiences for children on the autism spectrum.

The primary purpose of this paper is to present parents' perceptions of the literacy experiences of their young children on the autism spectrum at home and at school. In so doing we hope to generate knowledge of the specific literacy supports provided by parents to their children and present their views on what early literacy teaching methods and skill development strategies should look like for young children with autism. The challenges and barriers that parents face in supporting their young children in their foundation year of schooling is also examined.

\section{Method}

This research forms part of a larger longitudinal study investigating the early literacy performance of children on the autism spectrum. Ethical approval to conduct the study was granted by the university's Human Research Ethics Committee. As described in [Withheld for peer-review] children were seen at two time points, prior to and following their transition into formal schooling. At the second assessment time point, parents were invited to participate in an informal interview to share their thoughts on their child's literacy development and barriers and facilitators they had encountered. Data from these interviews are reported here.

\section{Participants}

The participants were 37 parents of children with ASD, 35 mothers and two fathers. In one interview both parents were present resulting in a total of 36 interviews. One mother also completed two interviews, one for each of her twin children. Interviews were completed in the home, at the university or within the child's prior early learning centre for children with autism. At the time of the interviews the children were aged between 5 years and 6 months, and 6 years and 9 months and had completed between $6-12$ months $(2-4$ school terms) of their foundation (first) year of schooling (Prep year in Queensland). 
Insert Table 1 here

Families were recruited for the original study through not-for-profit organisations for children on the autism spectrum, a Sydney children's hospital, and private speech pathology clinics. Families resided in the greater Brisbane area $(n=31)$ and metropolitan Sydney $(n=$ 6 ). Families that had participated in the original study were contacted via email or phone once their child entered their foundation year of schooling to determine interest in participating in a follow-up assessment. All children had a diagnosis of an autism spectrum disorder confirmed prior to participation in the original study. Researchers obtained written documentation pertaining to the child's diagnosis and the child's results on the Autism Diagnostic Observation Schedule (ADOS; Lord et al., 2012). If ADOS scores were unavailable, parents were asked to complete the Social Communication Questionnaire (SCQ; Rutter, Bailey, \& Lord, 2003). Consistent with Eaves, Wingert, Ho, and Mickelson (2006), a cut-off score of 11 or above on the SCQ was used to confirm diagnosis.

Inclusion in the original study required that the children could speak in short phrases/sentences and participate in preschool-like activities (for further details, see Westerveld et al., 2017). A measure of the child's cognitive functioning (non-verbal intelligence score) was determined using the Mullen Scales of Early Learning Developmental Quotient (DQ) (Mullen, 1995). DQ scores above 70 are considered to be within the normal limits. No child was excluded on the basis of their DQ score. Table 1 provides an overview of participant characteristics. Mothers' level of education was used as an indicator of socioeconomic status (SES). Parent report indicated that $30 \%$ of mothers had completed their secondary school education whilst $65 \%$ of mothers had gone beyond year 12 to complete tertiary studies. No data was available for two of the mothers.

\section{Data collection}

Semi-structured interviews, up to 15 minutes in length were completed in person at the time of the second assessment sessions by certified practising speech-language pathologists or a psychology $\mathrm{PhD}$ candidate. Parents were given the option of selecting the most appropriate and convenient location to complete the assessment sessions, namely at home, at the nearest university campus or within their child's previous early childhood centre. All interviews were completed within a quiet environment and were audio recorded for later transcription.

Interviewers were provided with a topic guide and were encouraged to ask probing questions when necessary to ensure coverage of all relevant areas.

\section{Data analysis}

Braun and Clarke's (2006) six phases of thematic analysis were manually applied with reference to Graneheim and Lundman's (2004) definitions of research concepts and procedure for greater specificity. Thematic analysis is described as a method of 'identifying, analysing and reporting patterns within data' (Braun \& Clarke, 2006) to investigate the perceptions and worldviews of social actors. The process used in the current study, as outlined in Braun and Clarke's (2006) phases of analysis, involved 1) familiarisation with the data, 2) division of the transcript into meaning units which are defined as related words, sentences or paragraphs which contain a central meaning (Graneheim \& Lundman, 2004) and assignment of a code to these meaning units, 3) collating related codes into broader categories and later themes, 4) reviewing and refining potential themes to ensure that they provide accurate representations of the codes they contain, 5) reviewing the themes together 
and discussing the overall narrative the themes portrayed, and 6) final analysis of the data and write-up of the research paper. Within this final stage of analysis, examples from the transcripts were selected to illustrate each of the themes. These examples were selected according to how clearly they presented the point being made.

\section{Results}

Three central themes emerged from the analysis of parents' views and experiences of literacy learning in their child's first year of formal schooling. These themes were 1) information that parents hold about their child, 2) strategies that parents use to engage their child in literacy learning and 3) concerns that parents raised about what is happening at school. These themes were identified as having multiple interrelated components which, together, described the challenges and facilitators to literacy learning that these parents have experienced.

\section{Parental expertise about their child}

The first theme to emerge - parental expertise about their child - captured the view that parents hold an extensive knowledge of their child's learning and factors that impact on their learning. Within this theme, parents highlighted the impact of challenging behaviours and described challenges that their child has faced as a result of learning difficulties and the presence of comorbidities.

\section{Behaviours of concern}

The impact of child behaviours of concern was highlighted by several parents attributing learning challenges to "selective" attention and participation, based on the child's perception of the relevance of the task and inclusion of his/her interests. P13 explains "at first I would have said...you could teach him anything, but it was his cooperation and...compliance". Similar thoughts were expressed by P22 "with [child] he's unwilling and selective, unless it's what he's interested in". These behaviours appear to be exacerbated when the child finds the task challenging, causing him/her to "hit a road block" (P19) or "won't tell you what he knows" (P19). A few parents proposed that rigidity of thought, consistent with characteristics of ASD, contributed to the child's willingness to participate in literacy activities, with some children having set ideas of where, when and with whom such activities are permissible. P3 explained: "as a parent it's really hard to try and teach him ... because he knows I'm the mum, I'm not supposed to do those things with him". P18 and P28 remarked that their child's refusal to complete literacy tasks at home led them to falsely underestimate their child's literacy abilities: "the teacher told us that he's skilled, we didn't see it to be honest. Apparently, he reads at a higher level for his teacher but he won't do it with us" (P28).

\section{Learning difficulties:}

Many parents reported that their child was experiencing difficulties learning literacyrelated skills, including letter-sound awareness and comprehension of spoken and written material. These difficulties were often compounded by an increased information processing time, with P21 commenting that her child needs "time to process, and then...time to express what he's understood". The cumulative effect of such learning difficulties is that children may fall below the academic expectations for their age and stage of schooling. P3 expressed 
such concerns: He's not keeping up, he's falling behind and now his teachers are scared... that he won't be able to keep up in grade 1.

\section{Comorbidities:}

In addition to the core autism characteristics, there exists the potential for the cooccurrence of a number of other physical and neurodevelopmental conditions. The most commonly reported conditions by parents were language delays and a poor attention span/Attention-Deficit Hyperactivity Disorder (ADHD). Several parents believed that delayed language abilities impaired their child's development of literacy skills, as P28 described "learning to read and write is infinitely more difficult to do...especially when you don't have the words to begin with". P20 expressed similar views suggesting "most ASD kids have that language delay so learning to read is so much trickier unless they've had really intensive speech therapy". Meanwhile, the presence of an attention deficit disorder is believed to be a "huge barrier" (P10), leading to a lack of focus and limited ability to absorb critical information: "getting him to focus on an activity for any length of time is very difficult" (P8). Other comorbidities identified by parents as impacting on literacy learning included poor fine motor control, sensory processing challenges, absent seizures and anxiety.

\section{Strategies that parents use to engage their child in literacy learning}

A second theme to emerge from the data related to the strategies that parents utilised to engage their children in literacy learning. As their child's first, and most enduring teacher, parents have developed and refined over time a suite of effective strategies to support their children's literacy acquisition.

\section{Encouraging child engagement}

It was evident from the analysis that parents used various strategies to encourage their child to engage in literacy learning activities. The most frequently reported are described. There was consensus among many parents that incorporating the child's interest into any learning activity was paramount, particularly for those with challenging behaviours. This is illustrated in a quote from P6: "It's more the motivation with [child], keeping her interested, so I'm happy to use anything on YouTube or whatever helps". This was reported to be significantly easier when the child's interests included aspects of literacy learning such as "his big interest in the alphabet" (P7). Parents described the "important thing" (P11) as including "anything that is of interest and is fun" (P11). Other strategies included utilising the child's strengths, as they are more likely to "continue doing something if he thinks he's doing well in it" (P23), providing rewards to motivate the child, and allowing "lots of breaks" (P18).

\section{Encouraging child understanding}

Parents commonly reflected on the necessity of strategies to assist their child's understanding of concepts and instructions. Given that children on the autism spectrum often present with comorbid receptive language difficulties, it is not surprising that many parents recommended the use of visual cues to support their understanding. Parents explained that their child "learns better when there is an activity and a visual associated with it" (P4) and that "using visuals has helped a lot" (P29). Simplifying instructions and concepts, such as "telling him what you want him to do in little steps" (P18), was also believed to benefit the 
child's learning. As P5 described "I believe that she can do everything that other kids can, she just needs to be communicated with in a way that she understands". Similarly, parents recommended "lots of repetition" (P18) and "multisensory cues" (P20) when teaching their child new concepts.

\section{Literacy learning activities}

Once these children started school, the parent's role as their first teacher continued. One parent expressed feelings of uncertainty regarding this role, specifying "no one can help me...I'm not a teacher...how do I teach her sight words? I don't know" (P13). Despite this confusion, several parents outlined the need to work with their child on literacy learning at home, as P3 explained:

Now we're going into grade 1 he's not prepared, so that gives me a lot of pressure over the holidays to try and bring him up, or at least keep him where he is so that he doesn't regress further. The school are trying to do the best they can...it's still not enough and it pushes back a lot of responsibility at home.

In order to target literacy learning at home, all parents reported reading regularly with their child including "school readers that we bring home" (P32) and books from the school or council library. Several parents also recognised reading comprehension difficulties in their child and were actively targeting this at home by "reading books and then asking questions out of it" (P10) and "talking about new words... what they mean" (P2). Other areas of literacy which were frequently practised at home included spelling, sight words, letter name and sound awareness, and writing tasks. Literacy programs, such as Reading Eggs and computer games, were frequently utilised by parents to encourage engagement in these target areas. This was illustrated by P3, who specified: "If we're on the computer we'll try to find things that have a learning element that are fun". Similarly, P9 expressed her belief that use of these programs was more enjoyable and therefore engaging for her son: "He's got games on his iPad that are spelling games, he loves doing them and he often picks them above other games". These comments emphasise the parental time which is dedicated to assisting children on the spectrum in their development of literacy learning. It is evident that parents hold valuable knowledge about their child's strengths, needs and interests and consistently utilise such knowledge to promote engagement and understanding in literacy.

\section{Parental concerns about their child's school experiences}

In the final theme, parents described the role of the school environment in shaping their perceptions of literacy learning for their child. Although some parents were satisfied with their child's school, the majority raised challenges and concerns that they, and their child, had encountered in the first year of formal education. This led to the third theme concerns that parents raised about what's happening in school.

\section{Teacher understanding of Autism Spectrum Disorders}

Feelings of frustration were shared by parents who believed that their child's teacher didn't understand the autism diagnosis and its impact on the child's learning. These difficulties and frustrations highlight barriers that parents face when the teachers lack education in autism spectrum disorders leading parents to believe that teaching staff "have no idea what to do". As a result, parents expressed concerns that their child wasn't being challenged in the classroom as teachers often accepted a lower standard of performance than 
their typically developing peers. This was illustrated in a statement by P26, "I think with [child] especially... at his school I feel that maybe he'll do something and because he has autism that'll do. They're kind of accepting a lower standard than what he is actually capable of".

One parent reflected feelings of helplessness as she struggled to find a way to help her daughter meet the academic demands of school, "I don't even know who to turn to...the teachers are at a loss" (P13). Another parent summarised, "teachers...don't understand that there's a lot more that goes into our kids than just being able to read. It's their environments, it's their sensory...their cognitive stuff, it's all of that" $(P 2)$. It was suggested that "having programs that are specifically designed for the core characteristics of ASD" would "enable every child the opportunity to actually learn" and afford children with "the same opportunities" (P3). P3 reflected:

Sometimes I liken it to children that are blind, how do they learn? Braille...these are tools that they need continuously, it's not a concession for them, they need it as a requirement to continue learning and growing. So why not put a specialised program in place [for kids on the autism spectrum]?

Conversely, teachers that understand the child's limitations and are "willing to listen" are perceived by parents to be positive influences on literacy learning, as one parent described; "the teacher that he has this year is well aware of his limitations and she has stuff in the classroom so if he's starting to get unfocused she'll give him finger puppets to play with...that's been really good" (P7).

\section{Delivery of the curriculum}

Many parents expressed concerns that the delivery of the academic curriculum did not cater for their child's individual needs. Parents argued an absence of "flexibility in how they present the curriculum" (P7) resulting from an education system which is "lacking in methodology" (P3) suitable for the needs of the child on the autism spectrum. Whilst many parents advocate for an inclusive educational approach one parent expressed her concerns that rather than tailoring the program to the child, as inclusion suggests, it is the child that is required to conform to the system. She commented: "it's not about inclusion, it's about conformity...they are expected as little square pegs to fit into round holes, sandpapering the edges to try and fit them into something that is not designed for them" (P3).

Many children on the spectrum are therefore falling "through the cracks" (P3) as their needs are not severe enough to attend special schools but they don't "meet base requirements in [mainstream] school" (P3). It was suggested that parents need to "find a school that is quite happy to change things around and give them the support they need" (P19) which reinforces several parents" beliefs that, currently, schools "are not designed for kids on the spectrum" (P3) as the teaching methodology is "not conducive to the way that their brains work (P5)". These quotes emphasise the urgent need for a change in the teaching approach within the classroom; moving from a curriculum-focus to a learner-focus which involves teaching individual children with consideration to their strengths, interests and capabilities.

\section{Communication}

Poor communication among school staff was identified as a barrier to learning success. This is illustrated in the views of P24 who believed that "getting everyone on the 
same page is virtually impossible" which has "been a little bit of a nightmare". Parents described miscommunication among staff and poor consolidation of ideas across the team as impacting on the support the child receives. This was explained in a quote from P24: "most teachers, the special education department, and the teacher aides have their own ideas about things, so basically it's a full team of people who get frustrated with each other and it comes out on the child. It can be quite cruel".

Parents also described their frustration with a lack of communication from the school: "school hasn't been informing us much about what's going on at school, we really don't know what happens there" (P23). This lack of communication with parents was reported to restrict their ability to support their child at home, as P3 described:

He's had all these issues and it's been the majority of the year for them to pick them up and talk to me ... it's only been in the last quarter that they have brought other issues to my attention...so at the end of prep I'm finding out that he's far behind, he's not got that understanding. Now we're going into grade 1 and he's not prepared.

This quote highlights a greater need for schools to acknowledge the parent's expertise and influence as their child's first teacher, and utilise this in order to support the child across contexts.

\section{School support}

While several parents agreed that there "is nowhere near enough support at school" (P9), this view was not shared by all parents. One parent reflected that her son's school was a "fantastic environment" (P24) and that "he's improved so much". Positive views of school systems were often attributed to "lots of support in the classroom" (P7) and staff taking an active role in assisting the child. For example, one parent (P27) explained: "They have the tiniest Special Education program of all the schools in the area but they seem to actually want to help". These quotes emphasise the impact that quality school support has on both student outcomes and parent satisfaction. It is evident from these parental views that quality support is of greater significance than quantity.

\section{Discussion}

The aim of this study was to present parents' perceptions of the literacy learning experiences of their young children on the autism spectrum at home and at school. We wanted to improve knowledge of the supports that parents provided to their children in developing literacy skills and gain an understanding of any barriers or facilitators to literacy learning that they experienced in the first year of school. Overall, three key themes emerged that emphasised the critical and ongoing role parents play as their child's first teacher.

Many parents of children on the autism spectrum raised concerns about their children's literacy learning capabilities based on observations of their child during the first 612 months of formal schooling. While all parents believed that their child was capable of literacy learning, the general consensus was that completing academic activities at home was often difficult due to a child's challenging behaviours or rigidity of thought limiting the child's willingness to participate. This finding is consistent with recent research which suggests that such challenging behaviours occur with greater severity in this population than in children that are typically developing or have an intellectual disability (McGuire et al., 2016; O’Nions, Happé, Evers, Boonen, \& Noens, 2018). Parents expressed their belief that 
these behaviours made engagement in learning activities particularly challenging at school and home, requiring special efforts to ensure activities were meaningful. Inclusion of special interests were frequently reported by parents as motivating their child to participate in literacy activities. Children on the autism spectrum have been found to demonstrate lower levels of interest in reading activities than peers with other disabilities, such as Down syndrome (Westerveld \& van Bysterveldt, 2017), which may account for some of these engagement difficulties. Language delays (receptive and/or expressive) were also identified as a commonly encountered challenge that hindered the child's ability to effectively participate in literacy learning. In order to compensate for this additional challenge and to supplement auditory information, parents commented that they often employed the use of visual supports (e.g., the use of pictures or line drawings to create a visual schedule of activities). Visual supports are an evidence-based practice which have been found to increase a student's ability to independently complete a task (Cohen \& Demchak, 2018; Wong et al., 2015).

All parents reported that they completed regular home literacy activities with their child, with several specifying that they felt responsible for ensuring that their child did not fall behind in the classroom. Because promoting academic success was common amongst all parents, the reading challenges their children experienced cannot be attributed to limited literacy learning opportunities at home. Instead, we suggest that the ability of the child on the autism spectrum to engage in effective literacy learning may be impacted by other factors, such as core autism characteristics (i.e. social communication difficulties or rigid behaviours/interests) and/or common comorbidities, such as anxiety, challenging behaviours, or attention-deficit disorders (Sberg et al., 2010). Parents identified a range of evidence-based strategies that they frequently incorporated to address such challenges at home. However difficulties were evident in the translation of such strategies across settings.

It has been well established that effective communication between educators and parents is essential for child participation and inclusion (Falkmer et al., 2015; LaBarbera, 2017; Stanley, Beamish, \& Bryer, 2005). However, some parents in the current study expressed a desire for increased two-way communication with their child's teacher. As students on the autism spectrum often require intensive support, parents may need more input and feedback regarding their child's behaviour, engagement and learning progress in the classroom. Such communication would enable educators to utilise the knowledge that parents hold about engaging their child in learning as well as inform parents on what and where to focus their attention at home to supplement their child's school learning. To achieve this goal upskilling of educators in fostering collaborative partnerships with parents may be required. Collaborative communication approaches have been found to enhance academic and socialemotional outcomes for children on the autism spectrum (Jeynes, 2011; Manz, Fantuzzo, \& Power, 2004; Sheridan et al., 2012) and may be beneficial in ensuring consistency across the home and school setting for all children with special learning needs (Azad et al., 2018).

Inclusion of a collaborative communication approach to parent-teacher communication may also aid in improving parent perceptions of school support, an area which was described by several parents as lacking. This is consistent with a 2006 study in which parents of children on the spectrum identified reciprocity of communication as a key factor in determining whether they felt listened to and trusted that educators were meeting the needs of their child (Renty \& Roeyers, 2006). Likewise, concerns parents raised about what is happening at school including the level of teachers' understanding of autism and the need for appropriate differentiation of the curriculum in order to support the needs of students with 
autism are consistent with previous Australian research (e.g., Lilley, 2015). Supporting parents, recognising their expertise and providing ongoing communication regarding their child's progress may allow them to feel more valued and empowered in supporting their child's literacy development.

Parents within the current study expressed frustrations and concerns that their child was not being taught literacy concepts in a way that best assisted their learning; reporting their belief that the academic curriculum lacked flexibility and individualism. Such perceived limitations with the curriculum were often suggested to be a causal factor in children falling below their academic expectations. This frustration was then amplified when parents felt that strategies to promote engagement and understanding of literacy concepts shared with the classroom teacher were used inconsistently. Conversely, parent satisfaction with their child's school was increased when teachers were open to parental communication and providing significant support to their child in the classroom. Whilst this 'learner-focused' approach is widely accepted in current teacher training, these data suggest that some teachers may still be having difficulties understanding the characteristics of ASD and implementing classroom wide strategies that respect and build on individual strengths and interests. This finding is supported in the literature with many mainstream teachers expressing concerns regarding their limited understanding of ASD and appropriate teaching strategies (Lindsay, Proulx, Thomson, \& Scott, 2013; Soto-Chodiman, Pooley, Cohen, \& Taylor, 2012; Yumak \& Akgul, 2010).

Studies of teacher perspectives suggest that teachers appreciate the benefits of effective strategies, however individualized education can be challenging and stressful without support and further knowledge in this area (Faisal, Tithi, \& Hossain, 2015; Majoko, 2016; Roberts \& Simpson, 2016; Soto-Chodiman et al., 2012; Yumak \& Akgul, 2010). The current study adds the parent perspective to this issue, highlighting that they too are aware that limitations in mainstream teacher knowledge may impact on their child's ability to effectively engage in literacy learning. Ongoing professional development opportunities should therefore be made readily available for teachers working with students with ASD to allow them to feel confident and supported in their own classrooms.

\section{Conclusion}

This article presents the findings of a study revealing parents' perceptions of the home and school literacy learning experiences of their young children on the autism spectrum. Whilst these perceptions represent a relatively small cohort of parents, they highlight the critical role that parents play in supporting their children's literacy development. The knowledge and insight of parents in relation to their child's dispositions to learning and teaching strategies that work position them as crucial partners with schools in the education of children on the autism spectrum. While individualized education models are certainly not a novel concept, this article builds on the current literature, highlighting the need for ongoing professional development opportunities to enable teachers to support students on the autism spectrum and, in turn, feel supported and confident in the classroom. This is particularly important given the increasing prevalence of ASD within Australian classrooms and increasing knowledge of the many challenges these children face in developing their literacy skills.

\section{Acknowledgements}


The authors sincerely thank the families who participated in this study for their time and commitment to the study and for sharing their opinions.

\section{Funding}

This study received financial support from the Cooperative Research Centre for Living with Autism, established and supported under the Australian Government's Cooperative Research Centres Program.

\section{References}

Adams, D., Young, K., \& Keen, D. (2019). Anxiety in children with autism at school: A systematic review. Review Journal of Autism and Developmental Disorders. doi:10.1007/s40489-019-00172-z

American Psychiatric Association. (2013). Diagnostic and statistical manual of mental disorders (5th ed.). Arlington, VA: American Psychiatric Publishing.

Arciuli, J., Stevens, K., Trembath, D., \& Simpson, I. C. (2013). The relationship between parent report of adaptive behavior and direct assessment of reading ability in children with autism spectrum disorder. Journal of Speech, Language, and Hearing Research, 56, 1837-1844. doi:10.1044/1092-4388(2013/12-0034)

Asberg, J., Kopp, S., Berg-Kelly, K., Gillberg, C. (2010). Reading comprehension, word decoding and spelling in girls with autism spectrum disorders (ASD) or attentiondeficit/hyperactivity disorder (AD/HD): performance and predictors. International Journal of Language \& Communication Disorders, 45, 61-71. doi:10.3109/13682820902745438

Australian Institute of Health and Welfare. (2017). Autism in Australia. Retrieved from https://www.aihw.gov.au/reports/disability/autism-in-australia/contents/autism

Azad, G., \& Mandell, D. S. (2016). Concerns of parents and teachers of children with autism in elementary school. Autism, 20, 435-441. doi:10.1177/1362361315588199

Azad, G. F., Marcus, S. C., Sheridan, S. M., \& Mandell, D. S. (2018). Partners in school: An innovative parent-teacher consultation model for children with autism spectrum disorder. Journal of Educational and Psychological Consultation, 1-27. doi:10.1080/10474412.2018.1431550

Baron-Cohen, S. (2000). Theory of mind in autism: A fifteen year review. In S. BaronCohen, H. Tager-Flusberg, \& D. J. Cohen (Eds.), Understanding other minds: Perspectives from developmental cognitive neuroscience (pp. 3-20). New York: Oxford University Press.

Barroso, N. E., Mendez, L., Graziano, P. A., \& Bagner, D. M. (2018). Parenting Stress through the Lens of Different Clinical Groups: a Systematic Review \& MetaAnalysis. Journal of Abnormal Child Psychology, 46, 449-461. doi:10.1007/s10802017-0313-6

Blair, K.-S. C., Lee, I.-S., Cho, S.-J., \& Dunlap, G. (2011). Positive Behavior Support Through Family-School Collaboration for Young Children With Autism. Topics in Early Childhood Special Education, 31, 22-36. doi:10.1177/0271121410377510

Braun, V., \& Clarke, V. (2006). Using thematic analysis in psychology. Qualitative research in psychology, 3, 77-101. doi:10.1191/1478088706qp063oa

Brown, H. M., Oram-Cardy, J., \& Johnson, A. (2013). A Meta-Analysis of the Reading Comprehension Skills of Individuals on the Autism Spectrum. Journal of Autism and Developmental Disorders, 43, 932-955. doi:10.1007/s10803-012-1638-1 
Chandler-Olcott, K., \& Kluth, P. (2009). Why everyone benefits from including students with autism in literacy classrooms. The Reading Teacher, 62, 548-557.

doi:10.1598/RT.62.7.1

Cohen, A., \& Demchak, M. (2018). Use of Visual Supports to Increase Task Independence in Students with Severe Disabilities in Inclusive Educational Settings. Education and training in autism and developmental disabilities, 53(1), 84-99.

Department of Education. (2018). Inclusive education policy statement. Brisbane, Qld: Queensland Government. Retrieved from https://education.qld.gov.au/student/inclusive-education/Documents/policy-statementbooklet.pdf

Deris, A. R., \& Di Carlo, C. F. (2013). Back to basics: working with young children with autism in inclusive classrooms: Autism and Inclusion. Support for Learning, 28, 5256. doi:10.1111/1467-9604.12018

Dynia, J. M., Brock, M. E., Logan, J. A. R., Justice, L. M., \& Kaderavek, J. N. (2016). Comparing children with ASD and their peers' growth in print knowledge. Journal of Autism and Developmental Disorders, 46, 2490-2500. doi:10.1007/s10803-0162790-9

Eaves, L., Wingert, H. D., Ho, H., \& Mickelson, E. C. (2006). Screening for autism spectrum disorders with the social communication questionnaire. Journal of Developmental and Behavioral Pediatrics, 27, s95-s103. doi:10.1097/00004703-200604002-00007

Faisal, R., Tithi, M., \& Hossain, S. (2015). Teachers'pPerspectives on the mainstreaming of autistic students in Bangladesh. Teacher's World, 42, 25-36.

Falkmer, M., Anderson, K., Joosten, A., \& Falkmer, T. (2015). Parents' perspectives on inclusive schools for children with autism spectrum conditions. International Journal of Disability, Development and Education, 62, 1-23. doi:10.1080/1034912X.2014.984589

Fleury, V. P., \& Schwartz, I. S. (2017). A modified dialogic reading intervention for preschool children with Autism Spectrum Disorder. Topics in Early Childhood Special Education, 37, 16-28. doi:10.1177/0271121416637597

Geurts, H. M., Verté, S., Oosterlaan, J., Roeyers, H., \& Sergeant, J. A. (2004). How specific are executive functioning deficits in attention deficit hyperactivity disorder and autism? Journal of Child Psychology and Psychiatry, 45, 836-854. doi:10.1111/j.1469-7610.2004.00276.x

Goldrich Eskow, K., Summers, J. A., Chasson, G. S., \& Mitchell, R. (2018). The association between family-teacher partnership satisfaction and outcomes of academic progress and quality of life for children/youth with autism: Family-teacher partnership. Journal of Policy and Practice in Intellectual Disabilities, 15, 16-25. doi:10.1111/jppi.12221

Graneheim, U. H., \& Lundman, B. (2004). Qualitative content analysis in nursing research: concepts, procedures and measures to achieve trustworthiness. Nurse Education Today, 24(2), 105-112. doi:10.1016/j.nedt.2003.10.001

Happé, F., \& Frith, U. (2006). The weak coherence account: Detail-focused cognitive style in autism spectrum disorders. Journal of Autism and Developmental Disorders, 36, 5-25. doi:10.1007/s10803-005-0039-0

Huemer, S. V., \& Mann, V. (2010). A Comprehensive Profile of Decoding and Comprehension in Autism Spectrum Disorders. Journal of Autism and Developmental Disorders, 40, 485-493. doi:10.1007/s10803-009-0892-3

Jang, J., Dixon, D. R., Tarbox, J., \& Granpeesheh, D. (2011). Symptom severity and challenging behavior in children with ASD. Research in Autism Spectrum Disorders, 5, 1028-1032. doi:https://doi.org/10.1016/j.rasd.2010.11.008 
Jeynes, W. H. ( 2011). Parental involvement and academic success. New York, NY: Routledge.

Keen, D., Webster, A., \& Ridley, G. (2016). How well are children with autism spectrum disorder doing academically at school? An overview of the literature. Autism, 20, 276-294. doi:10.1177/1362361315580962

Kohane, I. S., McMurry, A., Weber, G., MacFadden, D., Rappaport, L., Kunkel, L., . . . Churchill, S. (2012). The Co-Morbidity Burden of Children and Young Adults with Autism Spectrum Disorders. Plos One, 7(4), e33224. doi:10.1371/journal.pone.0033224

LaBarbera, R. (2017). A comparison of teacher and caregiver perspectives of collaboration in the education of students with Autism Spectrum Disorders. Teacher Education Quarterly, 44(3), 35-56.

Lilley, R. (2015). Trading places: Autism Inclusion Disorder and school change, International Journal of Inclusive Education, 19, 379-396, doi: 10.1080/13603116.2014.935813

Lindsay, S., Proulx, M., Thomson, N., \& Scott, H. (2013). Educators' challenges of including children with Autism Spectrum Disorder in mainstream classrooms. International Journal of Disability, Development and Education, 60, 347-362. doi:10.1080/1034912X.2013.846470

Lord, C., Rutter, M., DiLavore, P. C., Risi, S., Gotham, K., \& Bishop, S. (2012). Autism Diagnostic Observation Schedule - second edition: ADOS-2. Torrance, CA: Western Psychological Services.

Mackenzie, M., Cologon, K., \& Fenech, M. (2016). 'Embracing everybody' : Approaching the inclusive early childhood education of a child labelled with autism from a social relational understanding of disability. Australasian Journal of Early Childhood, 41(2), 4-12. Doi: 10.1177/183693911604100202

Majoko, T. (2016). Inclusion of children with Autism Spectrum Disorders: Listening and hearing to voices from the grassroots. Journal of Autism and Developmental Disorders, 46(4), 1429-1440. doi:10.1007/s10803-015-2685-1

Manz, P. H., Fantuzzo, J. W., \& Power, T. J. (2004). Multidimensional assessment of family involvement among urban elementary students. Journal of School Psychology, 42, 461-475. doi:10.1016/j.jsp.2004.08.002

Matson, J. L., Wilkins, J., \& Macken, J. (2008). The Relationship of Challenging Behaviors to Severity and Symptoms of Autism Spectrum Disorders. Journal of Mental Health Research in Intellectual Disabilities, 2, 29-44. doi:10.1080/19315860802611415

McGuire, K., Fung, L. K., Hagopian, L., Vasa, R. A., Mahajan, R., Bernal, P., . . . Whitaker, A. H. (2016). Irritability and problem behavior in Autism Spectrum Disorder: A practice pathway for pediatric primary care. Pediatrics, 137, S136-S148. doi:10.1542/peds.2015-2851L

McIntyre, N. S., Solari, E. J., Grimm, R. P., E. Lerro, L., E. Gonzales, J., \& Mundy, P. C. (2017). A Comprehensive Examination of Reading Heterogeneity in Students with High Functioning Autism: Distinct Reading Profiles and Their Relation to Autism Symptom Severity. Journal of Autism and Developmental Disorders, 47, 1086-1101. doi:10.1007/s10803-017-3029-0

Mullen, E. M. (1995). Mullen Scales of Early Learning Circle Pines, MN: American Guidance Service.

Murphy, K. A., Justice, L. M., O’Connell, A. A., Pentimonti, J. M., \& Kaderavek, J. N. (2016). Understanding risk for reading difficulties in children with language 
impairment. Journal of Speech, Language, and Hearing Research, 59, 1436-1447. doi:10.1044/2016 JSLHR-L-15-0110

Nation, K., Clarke, P., Wright, B., \& Williams, C. (2006). Patterns of Reading Ability in Children with Autism Spectrum Disorder. Journal of Autism and Developmental Disorders, 36, 911-919. doi:10.1007/s10803-006-0130-1

Nation, K., Cocksey, J., Taylor, J. S. H., \& Bishop, D. V. M. (2010). A longitudinal investigation of early reading and language skills in children with poor reading comprehension. Journal of child psychology and psychiatry, 51, 1031-1039.

O’Nions, E., Happé, F., Evers, K., Boonen, H., \& Noens, I. (2018). How do Parents Manage Irritability, Challenging Behaviour, Non-Compliance and Anxiety in Children with Autism Spectrum Disorders? A Meta-Synthesis. Journal of Autism and Developmental Disorders, 48, 1272-1286. doi:10.1007/s10803-017-3361-4

Pullen, P. C., \& Justice, L. M. (2003). Enhancing Phonological Awareness, Print Awareness, and Oral Language Skills in Preschool Children. Intervention in School and Clinic, 39, 87-98. doi:10.1177/10534512030390020401

Puranik, C. S., Lonigan, C. J., \& Kim, Y.-S. (2011). Contributions of emergent literacy skills to name writing, letter writing, and spelling in preschool children. Early Childhood Research Quarterly, 26, 465-474. doi:10.1016/j.ecresq.2011.03.002

Renty, J., \& Roeyers, H. (2006). Satisfaction with formal support and education for children with autism spectrum disorder: the voices of the parents. Child: Care, Health and Development, 32, 371-385. doi:10.1111/j.1365-2214.2006.00584.x

Rutter, M., Bailey, M. D., \& Lord, C. (2003). The Social Communication Questionnaire $(S C Q)$. Los Angeles, CA: Western Psychological Services.

Saggers, B., Klug, D., Harper-Hill, K., Ashburner, J., Costley, D., Clark, T., . . Carrington, S. (2015). Australian autism educational needs analysis-What are the needs of schools, parents and students on the autism spectrum? Full report. Cooperative Research Centre for Living with Autism, Brisbane. Retrieved from https://www.autismcrc.com.au/sites/default/files/inlinefiles/Educational\%20needs\%20analysis\%20-\%20Final\%20report.pdf

Schultz, T. R., Able, H., Sreckovic, M. A., \& White, T. (2016). Parent-Teacher Collaboration: Teacher Perceptions of What is Needed to Support Students with ASD in the Inclusive Classroom. Education and Training in Autism and Developmental Disabilities, 51, 344-354. Retrieved from http://www.jstor.org/stable/26173862

Shepherd, K. G., \& Kervick, C. T. (2016). Enhancing collaborative leadership among parents of children with disabilities: New directions for policy and practice. Journal of Disability Policy Studies, 27, 32-42. doi:10.1177/1044207315576081

Sheridan, S. M., Bovaird, J. A., Glover, T. A., Andrew G.S., Witte, A., \& Kwon, K. (2012). A randomized trial examining the effects of conjoint behavioral consultation and the mediating role of the parent-teacher relationship. School Psychology Review, 41, 23 46.

Roberts, J., \& Simpson, K. (2016). A review of research into stakeholder perspectives on inclusion of students with autism in mainstream schools. International Journal of Inclusive Education, 20, 1084-1096. doi:10.1080/13603116.2016.1145267

Soto-Chodiman, R., Pooley, J. A., Cohen, L., \& Taylor, M. F. (2012). Students with ASD in mainstream primary education settings: Teachers' experiences in Western Australian classrooms. Australasian Journal of Special Education, The, 36, 97-111. doi:10.1017/jse.2012.10

Stanley, A., Beamish, W., \& Bryer, F. (2005). Communication between home and school about children with autistic spectrum disorder in primary schools. Stimulating the 'Action' as Participants in Participatory Research, 3, 113-122. 
Teale, W. H., \& Sulzby, E. (1986). Emergent literacy: Writing and reading. Norwood, NJ: Ablex.

Tucker, V., \& Schwartz, I. (2013). Parents' perspectives of collaboration with school professionals: barriers and facilitators to successful partnerships in planning for students with ASD. School Mental Health, 5, 3-14. doi:10.1007/s12310-012-9102-0

Turnbull, A. P., Turnbull, H. R., ,, Erwin, E. J., Soodak, L. C., \& Shogren, K. A. (2015). Families, professionals, and exceptionality: positive outcomes through partnerships and trust. (Seventh Edition). Upper Saddle River, N.J: Pearson.

van Bergen, E., Van Zuijen, T. L., Bishop, D., \& de Jong, P. F. (2017). Why are home literacy environment and children's reading skills associated? What parental skills reveal. Reading Research Quarterly, 52, 147-160. doi:10.1002/rrq.160

Volkmar, F., Siegel, M., Woodbury-Smith, M., King, B., McCracken, J., State, M., \& American Academy of Child and Adolescent Psychiatry (AACAP) Committee on Quality Issues (CQI). (2014). Practice parameter for the assessment and treatment of children and adolescents with Autism Spectrum Disorder. Journal of the American Academy of Child \& Adolescent Psychiatry, 53, 237-257.

Westerveld, M., \& van Bysterveldt, A. K. (2017). The Home Literacy Environment of Preschool-Age Children with Autism or Down Syndrome. Folia Phoniatrica et Logopaedica, 69, 43-53. doi:10.1159/000475840

Westerveld, M. F., Paynter, J., O'Leary, K., \& Trembath, D. (2018). Preschool predictors of reading ability in the first year of schooling in children with ASD. Autism Research, 11, 1332-1344. doi:10.1002/aur.1999

Westerveld, M. F., Paynter, J., Trembath, D., Webster, A. A., Hodge, A. M., \& Roberts, J. (2017). The emergent literacy skills of preschool children with autism spectrum disorder. Journal of Autism and Developmental Disorders, 47, 424-438. doi:10.1007/s10803-016-2964-5

Westerveld, M. F., Trembath, D., Shellshear, L., \& Paynter, J. (2016). A systematic review of the literature on emergent literacy skills of preschool children with autism spectrum disorder. The Journal of Special Education, 50(1), 37-48. doi:10.1177/0022466915613593

Wong, C., Odom, S. L., Hume, K. A., Cox, A. W., Fettig, A., Kucharczyk, S., . . Schultz, T. R. (2015). Evidence-based practices for children, youth, and young adults with autism spectrum disorder: A comprehensive review. Journal of Autism and Developmental Disorders, 45, 1951-1966. doi:10.1007/s10803-014-2351-z

Yumak, N., \& Akgul, E. M. (2010). Investigating elementary school administrators' and teachers' perceptions on children with autism. Procedia - Social and Behavioral Sciences, 2, 910-914. doi:10.1016/j.sbspro.2010.03.125

Zablotsky, B., Boswell, K., \& Smith, C. (2012). An evaluation of school involvement and satisfaction of parents of children with autism spectrum disorders. American Journal on Intellectual and Developmental Disabilities, 117, 316-330. doi:10.1352/19447558-117.4.316 
Table 1. Participants

\begin{tabular}{|c|c|c|c|c|}
\hline \multicolumn{3}{|c|}{ Adult characteristics } & \multicolumn{2}{|l|}{$\mathbf{N}(\%)$} \\
\hline \multirow[t]{2}{*}{ Gender } & \multicolumn{2}{|l|}{ Female } & \multicolumn{2}{|l|}{$35(94.6)$} \\
\hline & \multicolumn{2}{|l|}{ Male } & \multicolumn{2}{|c|}{$2(5.4 \%)$} \\
\hline \multirow[t]{3}{*}{ Age } & \multicolumn{2}{|l|}{$21-30$} & \multicolumn{2}{|l|}{$3(8.1)$} \\
\hline & \multicolumn{2}{|l|}{$31-40$} & \multicolumn{2}{|c|}{$20(54.1)$} \\
\hline & \multicolumn{2}{|l|}{$41-50$} & \multicolumn{2}{|c|}{$12(32.4)$} \\
\hline \multirow{2}{*}{$\begin{array}{l}\text { Mother's highest level of } \\
\text { education }\end{array}$} & \multicolumn{2}{|l|}{ Secondary } & \multicolumn{2}{|c|}{$11(30.5)$} \\
\hline & \multicolumn{2}{|l|}{ Tertiary } & \multicolumn{2}{|c|}{$24(63.8)$} \\
\hline \multicolumn{5}{|c|}{ Child characteristics } \\
\hline & $n$ & Mean & Range & SD \\
\hline Gender $(\mathrm{M} / \mathrm{F})$ & $32 / 5$ & & & \\
\hline Age (months) & 37 & 73.5 & $66-81$ & 4.7 \\
\hline Months of schooling & 37 & 9.2 & $6-12$ & 1.9 \\
\hline Developmental Quotient & 37 & 78.6 & $44-119$ & 20.9 \\
\hline SCQ & 37 & 16 & $5-32$ & 6.2 \\
\hline
\end{tabular}

Note. SCQ: Social Communication Questionnaire (raw score). 